\title{
Additional Surgical Method Aimed to Increase Distractive Force during Occipitocervical Stabilization : Technical Note
}

\author{
Veysel Antar, M.D., Okan Turk, M.D. \\ Department of Neurosurgery, Istanbul Research and Training Hospital, Istanbul, Turkey
}

Objective : Craniovertebral junctional anomalies constitute a technical challenge. Surgical opening of atlantoaxial joint region is a complex procedure especially in patients with nuchal deformity like basilar invagination. This region has actually very complicated anatomical and functional characteristics, including multiple joints providing extension, flexion, and wide rotation. In fact, it is also a bottleneck region where bones, neural structures, and blood vessels are located. Stabilization surgery regarding this region should consider the fact that the area exposes excessive and life-long stress due to complex movements and human posture. Therefore, all options should be considered for surgical stabilization, and they could be interchanged during the surgery, if required.

Methods : A 53-year-old male patient applied to outpatients' clinic with complaints of head and neck pain persisting for a long time. Physical examination was normal except increased deep tendon reflexes. The patient was on long-term corticosteroid due to an allergic disease. Magnetic resonance imaging and computed tomography findings indicated basilar invagination and atlantoaxial dislocation.The patient underwent C0-C3-C4 (lateral mass) and additional C0-C2 (translaminar) stabilization surgery.

Results : In routine practice, the sites where rods are bound to occipital plates were placed as paramedian. Instead, we inserted lateral mass screw to the sites where occipital screws were inserted on the occipital plate, thereby creating a site where extra rod could be bound.When C2 translaminar screw is inserted, screw caps remain on the median plane, which makes them difficult to bind to contralateral system. These bind directly to occipital plate without any connection from this region to the contralateral system.Advantages of this technique include easy insertion of C2 translaminar screws, presence of increased screw sizes, and exclusion of pullout forces onto the screw from neck movements. Another advantage of the technique is the median placement of the rod; i.e., thick part of the occipital bone is in alignment with axial loading.

Conclusion : We believe that this technique, which could be easily performed as adjuvant to classical stabilization surgery with no need for special screw and rod, may improve distraction force in patients with low bone density.

Key Words : Spine · Craniovertebral · Screws.

- Received : June 24, 2017 •Revised : July 26, 2017 •Accepted : August 23, 2017

- Address for reprints : Veysel Antar, M.D.

Department of Neurosurgery, Istanbul Research and Training Hospital, Org. Abdurrahman Nafiz Gürman Cad. Etyemez, Samatya, Istanbul 34098, Turkey Tel : +90-212-4596000, Fax : +90-212-4596230, E-mail : veyselantar@gmail.com

This is an Open Access article distributed under the terms of the Creative Commons Attribution Non-Commercial License (http://creativecommons.org/licenses/by-nc/4.0) which permits unrestricted non-commercial use, distribution, and reproduction in any medium, provided the original work is properly cited. 


\section{INTRODUCTION}

Craniovertebral junctional anomalies constitute a technical challenge. Surgical opening of atlantoaxial joint region is a complex procedure especially in patients with nuchal deformity like basilar invagination ${ }^{9}$. This region has actually very complicated anatomical and functional characteristics, including multiple joints providing extension, flexion, and wide rotation. In fact, it is also a bottleneck region where bones, neural structures, and blood vessels are located ${ }^{17)}$.

Stabilization surgery regarding this region should consider the fact that the area exposes excessive and life-long stress due to complex movements and human posture ${ }^{8)}$. Therefore, all options should be considered for surgical stabilization, and they could be interchanged during the surgery, if required. Surgical treatment of this region is composed of decompression and stabilization. Bone quality of the surgical candidate is very critical for stabilization.

We aimed to report on a surgical technique performed adjuvant to the standard occipitocervical stabilization surgery to improve distractive force in a patient with low bone quality. routine practice, the sites where rods are bound to occipital plates were placed as paramedian. Instead, we inserted polyaxial screw to the sites where occipital screws were inserted on the occipital plate, thereby creating a site where extra rod could be bound. When C2 translaminar screw is inserted, screw caps remain on the median plane, which makes them difficult to bind to contralateral system. These bind directly to occipital plate without any connection from this region to the contralateral system.

Advantages of this technique include easy insertion of C2 translaminar screws, presence of increased screw sizes, and exclusion of pullout forces onto the screw from neck movements. Another advantage of the technique is the median placement of the rod; i.e., thick part of the occipital bone is in alignment with axial loading.

This technique could allow for more powerful axial loading by independent insertion from the existing system in such surgeries where C2 lamina is preserved. Besides, it does not require any additional kit or design since screws used in occipital region are already included in the current kit. In addition, the rod may be bound to desired region since screw holes on the occipital plates are used (Fig. 2).

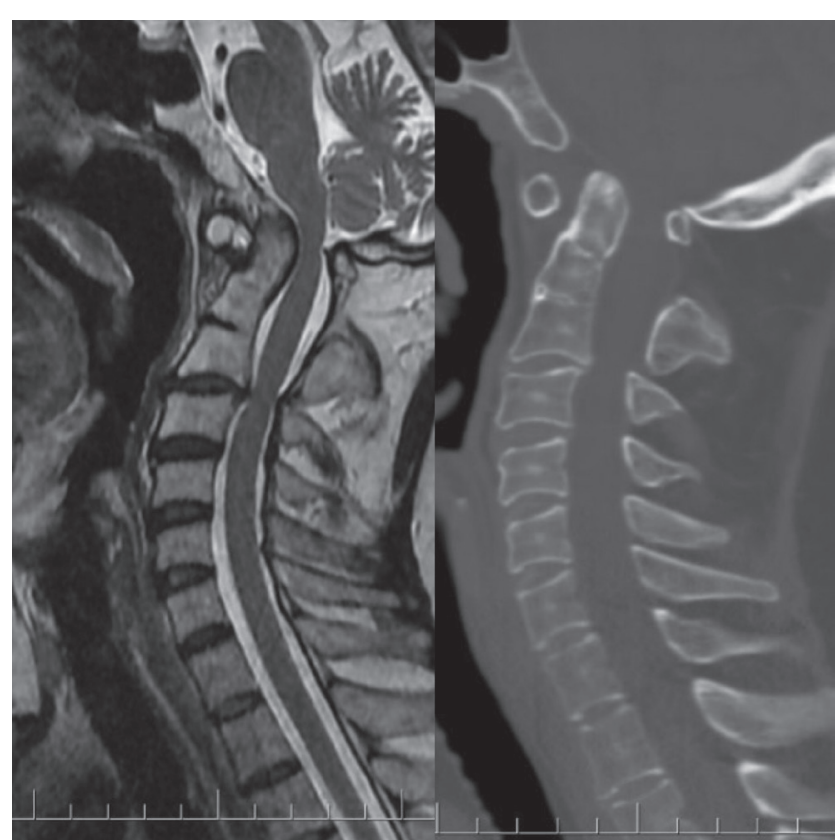

Fig. 1. Magnetic resonance imaging and computed tomography findings indicated basilar invagination and atlantoaxial dislocation. 


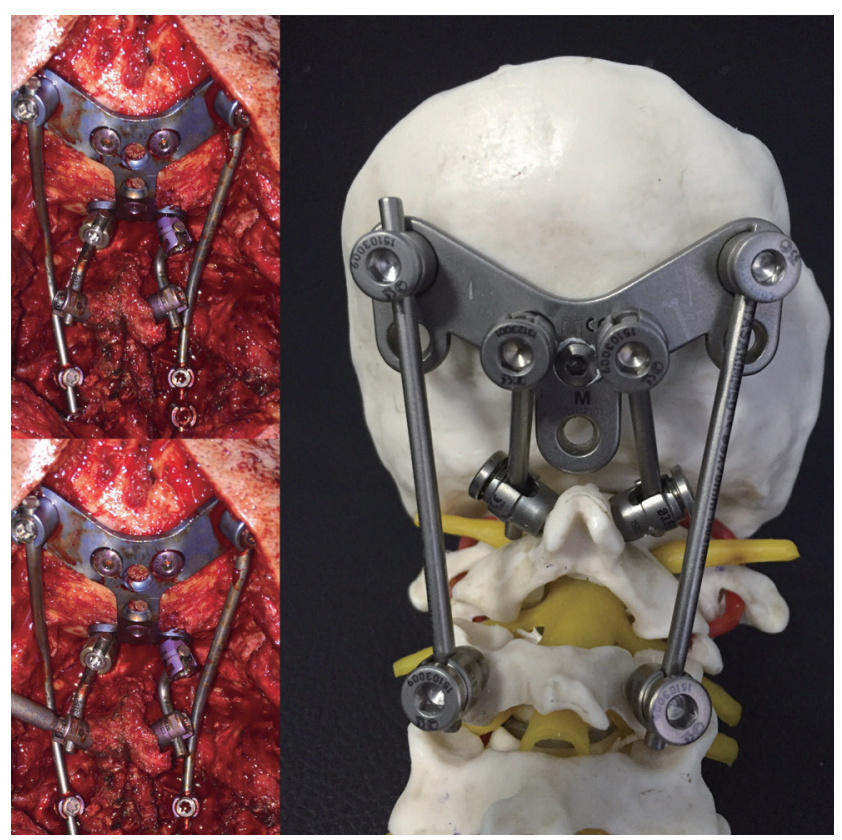

Fig. 2. The sites where rods are bound to occipital plates were placed as paramedian. Instead, we inserted lateral mass screw to the sites where occipital screws were inserted on the occipital plate, thereby creating a site where extra rod could be bound.

\section{DISCUSSION}

Craniovertebral junction is a complex structure due to presence of bones, neural tissues, and arteries. Mobilization of this region is provided by involvement of multiple joints. Therefore, surgical success rate depends on a successful stabilization, where many surgical techniques have been tried so far.

We hereby report an easy-to-perform surgical technique that may be done as adjuvant to previously defined surgical techniques.

Stabilization surgery of this region can be divided into two, as anterior and posterior stabilization ${ }^{17)}$. In fact, higher number of surgical technique was described for the latter. Interlaminar grafting and wiring methods in posterior atlantoaxial fixation was first described by Gallie, which was then modified by Brooks and Jenkins ${ }^{1)}$ and others ${ }^{2,6)}$. Failure of these techniques was highly probable due to relaxation of wires and melting the bony graft inserted. These led to development of plate and rod systems. Goel and Laher were the first to describe the stabilization of $\mathrm{C} 2$ and $\mathrm{C} 1$ lateral mass with anchor screw, which required cutting of $\mathrm{C} 2$ root to stabilize $\mathrm{C} 1$ and $\mathrm{C} 2$ with plate ${ }^{7}$. In addition, Harms and Melcher ${ }^{5}$ in their study of 2001 used polyaxial screw instead of anchor screw on C2, and fixed it with the rod.

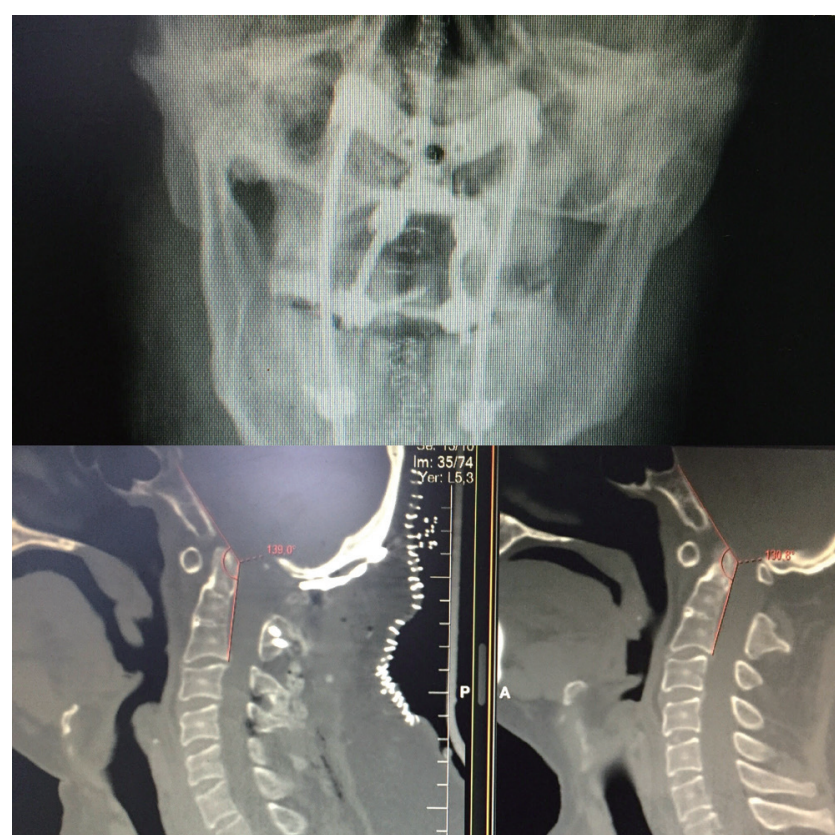

Fig. 3. Postoperative images showed narrowed atlantodental interval with relief of compression on the spinal nerve.

The technique was further modified by replacement with translaminar screw by Wright in 2004, which was called as GoelHarms-Wright method ${ }^{14}$. Except this method, screw stabilization of C1 lateral mass include also Tan method ${ }^{18)}$ and Notch method $^{11)}$. Cutting of $\mathrm{C} 2$ nerve root may be a shared feature of all these techniques. $\mathrm{C} 2$ pedicle screw ensures a relatively rigid stabilization, which constitutes the first option for this region. Major disadvantage of this screw is that pedicle diameter could not have a small size and it is anteriorly related to carotid artery, which makes it prone to injury by screw's tip ${ }^{17)}$. Stabilization with transarticular screw was first developed by Mayers and Seeman in 1987. This method provides very rigid fixation with high fusion rates ${ }^{12,13)}$.

Limitations of this technique include high riding vertebral artery, pedicle thickness, and insertion angle of screw ${ }^{3}$. C2 translaminar screw was first described by Wright in $2004^{19)}$. It might be used in patients where stabilization with $\mathrm{C} 2$ pedicle screw was troublesome (in case of high riding vertebral artery or small pedicle diameter). Biomechanistic studies showed it had comparable stability to pedicle screw ${ }^{10}$. Advantages of translaminar screw are ease of applicability, no need for fluoroscopy, no relation with vertebral artery, and similar amount of stabilization as pedicle screw. The only disadvantage is the difficulty of connection to other systems. Occipitocervical stabilization was 
first performed in 1980s with Ransford loop as the standard method $^{15,16}$. This method was performed by wire-binding of shaped rod to the occipital bone and cervical laminae. After 20 years of usage, the Olerud cervical fixation system was introduced in 1997. Short segment fixation with C0-C2 translaminar screw or pedicle screw provides a very strong stabilization in patients stabilized under C2. Similarly, their midline or bicortical placements were very strong in the relation of occipital plate to the occipital bone $e^{4)}$.

In addition, there are hybrid techniques in the literature where translaminar screw and various connections are simultaneously used ${ }^{3,14,20)}$. In our case, we tried to strengthen the stabilization by adding two rods to the midline adjuvant to stabilization of the occipital bone with classical pedicle and lateral mass. Postoperative CT and MRI images showed narrowed atlantodental interval with relief of compression on the spinal nerve (Fig. 3). This method may be added to the occipitocervical stabilization by 2 extra rods without a need for any additional material. Moreover, rod may be connected to the desired site of the occipital plate, and difficulties regarding rod connection could be overcome.

\section{CONCLUSION}

We believe that this technique, which could be easily performed as adjuvant to classical stabilization surgery with no need for special screw and rod, may improve distraction force in patients with low bone density.

\section{CONFLICTS OF INTEREST}

The authors have no financial conflicts of interest.

\section{INFORMED CONSENT}

Informed consent was obtained from all individual participants included in this study.

\section{References}

1. Brooks AL, Jenkins $E B$ : Atlanto-axial arthrodesis by the wedge compression method. J Bone Joint Surg Am 60 : 279-284, 1978

2. Dickman CA, Sonntag VK, Papadopoulos SM, Hadley MN : The interspinous method of posterior atlantoaxial arthrodesis. J Neurosurg 74 : 190-198, 1991

3. Du S, Ni B, Lu X, Xie N, Guo X, Guo Q, et al. : Application of unilateral C2 translaminar screw in the treatment for atlantoaxial ilnstability as an alternative or salvage of pedicle screw fixation. World Neurosurg 97 : 86-92, 2017

4. Haher TR, Yeung AW, Caruso SA, Merola AA, Shin T, Zipnick Rl, et al. : Occipital screw pullout strength. A biomechanical investigation of occipital morphology. Spine (Phila Pa 1976) 24 : 5-9, 1999

5. Harms J, Melcher RP : Posterior C1-C2 fusion with polyaxial screw and rod fixation. Spine (Phila Pa 1976) 26 : 2467-2471, 2001

6. Gallie WE : Fractures and dislocations of the cervical spine. Am J Surg $46:$ 495-499, 1939.

7. Goel A, Laheri V : Plate and screw fixation for atlanto-axial subluxation. Acta Neurochir (Wien) $129:$ 47-53, 1994

8. Goel A : Is inclusion of the occipital bone necessary/counter-effective for craniovertebral junction stabilization? J Craniovertebr Junction Spine 6 : 102-104, 2015

9. Goel A, Jankharia B, Shah A, Sathe P : Three-dimensional models: an emerging investigational revolution for craniovertebral junction surgery. J Neurosurg Spine 25 : 740-744, 2016

10. Gorek J, Acaroglu E, Berven S, Yousef A, Puttlitz CM : Constructs incorporating intralaminar C2 screws provide rigid stability for atlantoaxial fixation. Spine (Phila Pa 1976) 30 : 1513-1518, 2005

11. Lee MJ, Cassinelli E, Riew KD : The feasibility of inserting atlas lateral mass screws via the posterior arch. Spine Spine (Phila Pa 1976) 31 : 27982801, 2006

12. Magerl F, Seeman PS : Stable posterior fusion of the atlas and axis by transarticular screw fixation in Kehr P, Weider A (eds) : Cervical Spine I. Vienna : Spinger, 1987, pp322-327

13. Marcotte P, Dickman CA, Sonntag VK, Karahalios DG, Drabier J : Posterior atlantoaxial facet screw fixation. J Neurosurg 79 : 234-237, 1993

14. Mendelsohn D, Dea N, Lee R, Boyd MC : Bilateral pedicle and crossed translaminar screws in C2. Asian Spine J 9 : 783-788, 2015

15. Menezes $A H$ : Dorsal occipitocervical fusion: rod and wiring techniques in Kim DM, Vaccaro AR, Fessler RG (eds) : Spinal Instrumentation: Surgical Techniques. New York: Thieme Medical Publishers, 2005, pp14-19

16. Ransford AO, Crockard HA, Pozo JL, Thomas NP, Nelson IW : Craniocervical instability treated by contoured loop fixation. J Bone Joint Surg Br 68 : 173-177, 1986

17. Takayasu M, Aoyama M, Joko M, Takeuchi M : Surgical Intervention for instability of the craniovertebral junction. Neurol Med Chir (Tokyo) 56 : 465-475, 2016

18. Tan M, Wang H, Wang Y, Zhang G, Yi P, Li Z, et al. : Morphometric evaluation of screw fixation in atlas via posterior arch and lateral mass. Spine 
Four Rod | Antar V, et al.

(Phila Pa 1976) $28: 888-895,2003$

19. Wright NM : Posterior C2 fixation using bilateral, crossing C2 laminar screws: case series and technical note. J Spinal Disord Tech 17 : 158162,2004
20. Yew A, Lu D, Lu DC : CT-based morphometric analysis of C1 laminar dimensions: $\mathrm{C} 1$ translaminar screw fixation is a feasible technique for salvage of atlantoaxial fusions. Surg Neurol Int 6(Suppl 4) : S236S239, 2015 